\title{
Research on the Relationship Between Self-improvement Values and Green Brand Identity
}

\author{
Xuedong Liang ${ }^{1}$, Yong Yang ${ }^{1}$, Qunxi Gong ${ }^{1,2}$ Sipan $\mathrm{Li}^{1}$, and Gengxuan Guo ${ }^{1 *}$ \\ ${ }^{1}$ Business School, Sichuan University, Chengdu, China \\ ${ }^{2}$ Sichuan Haina Rendong Science and Technology Co. Ltd.
}

\begin{abstract}
In order to clarify the relationship between self-improvement values and green brand identity, we take the consumers' self-improvement values as the antecedent variable, consider the self-monitoring as the moderating variable, regard consumers' environmental self-accountability as the intermediary variable, and conduct an empirical analysis of the impact of consumers' self-improvement values on green brand identity. The research found that:1) Self-improvement values positively affect consumers' recognition of green brands;2) Self-improvement values positively affect consumers' environmental self-accountability;3) Environmental self-accountability positively mediates the relationship between self-improvement values and green brand identity;4) Self-monitoring positively regulates the impact of consumer values on consumers' environmental self-accountability and the mediating role of environmental self-accountability.
\end{abstract}

\section{Introduction}

Existing research mainly focuses on the influence of brand identity on brand loyalty [1]. Few scholars have tried to explore the factors that affect consumers' brand identity in an empirical way [2]. And how consumers' personal values affect consumers' identity with green brands has not been studied yet.

This article aims to prove that the relationship among consumers' self-improvement values, consumers' environmental self-accountability, and consumer green brand identity, especially self-improvement values, which is generally considered to be negatively related to consumers' green behaviors by scholars. In order to fill these gaps, this article constructs a theoretical framework to explore the impact of individual self-improvement values on green brand identity and its mechanism, as well as the boundary conditions for environmental selfaccountability. Therefore, this article not only enriches the research on the influence of the psychological factor of self-improvement values, but also provides a theoretical basis for the research on green brand identity.

\section{Theory and Hypothesis}

\subsection{The influence of self-improvement values on green brand identity}

Self-improvement values emphasize power, achievement and hedonism, and pay more attention to the promotion of personal interests. Consumers with self-improvement values may be respected by others due to their perception of protecting nature and saving resources, thereby enhancing their social status. This expected positive result will encourage consumers with self-improvement values to recognize the benefits of green brands, and thus recognize green brands. Secondly, the high-quality and high-value characteristics of green brands are consistent with the self-improvement values of consumers' achievements, hedonism and other values, which will also promote self-improvement consumers to identify with green brands.

Accordingly, the following hypothesis is proposed:

Hypothesis 1: Self-improvement values positively affect consumers' recognition of green brands.

\subsection{The impact of environmental self- accountability on green brand identity}

Previous studies have shown that environmental selfaccountability has a very important impact on green consumption, and enhancing consumers' environmental self-accountability can increase consumers' preference for green products [3]. Brand identity is the degree of consistency or similarity between the brand image perceived by consumers and the individual's own values, personality, and lifestyle. Consumers are more likely to feel that the brand they choose will bring the expected benefits to them, so that consumers have a higher degree of recognition of green brands.

Accordingly, the following hypothesis is proposed:

Hypothesis 2: Environmental self-accountability positively affects green brand identity.

\footnotetext{
*Corresponding author: ggx0056@hotmail.com
} 


\subsection{The intermediary role of environmental self- accountability}

Environmental standards are determined by formal rules or informal norms and values related to specific decisions or actions [4]. When consumers with self-improvement values, who prefer achievement, power and hedonism, perceive their green consumption behaviors, they may show their taste and strength (achievement) because of the high prices of green products; At the same time, the proenvironmental characteristics of green brands are conducive to the promotion of the social status the recognition of others (power) for such consumers and; This makes it easier for consumers to activate selfstandards and have stronger environmental selfaccountability. Consumers are more aware of their green consumption behavior and increase their satisfaction with green brands and their willingness to pursue green brands. In turn, consumers are more willing to identify with green brands.

Accordingly, the following hypothesis are proposed:

Hypothesis 3: Environmental self-accountability positively affects green brand identity.

Hypothesis 4: Environmental self-accountability plays an intermediary role between self-improvement values and green brand identity

\subsection{Self-monitoring}

Any individual is in a continuous band from low selfmonitoring to high self-monitoring. People with high levels of self-monitoring show stronger image awareness than those with low levels of self-monitoring. Consumers with self-improvement values are driven by values such as achievement, power, and hedonism, and desire to be respected by others and recognized by society. At the same time, self-monitoring is also eager to be accepted by others and recognized by society [5]. Therefore, the two have reached a highly consistent image awareness, which makes it easier for consumers to adjust for inconsistencies in values and behaviors. That is, tend to make changes in order to achieve the desired end state, which makes it easier for consumers to initiate environmental selfaccountability.

Accordingly, the following hypothesis are proposed:

Hypothesis 5: Self-monitoring positively regulates self-improvement values and environmental selfaccountability.

Hypothesis 6: Self-monitoring positively regulates the mediating role of environmental self-accountability.

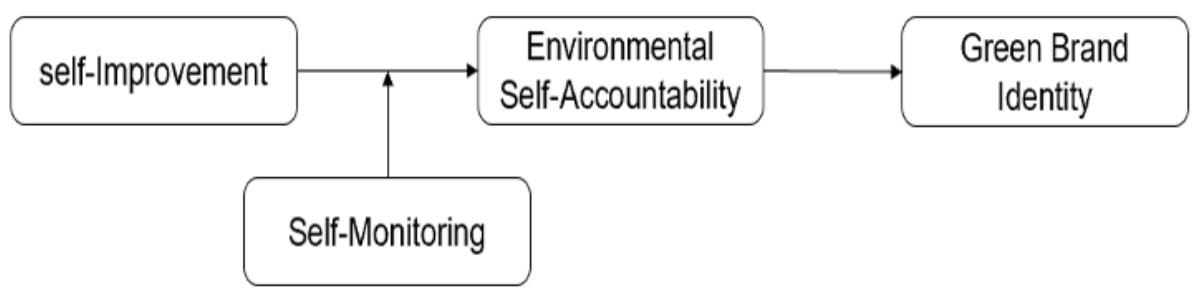

Figure 1. Theoretical framework

\section{Methods}

\subsection{Sample and Procedure}

This study uses a questionnaire survey to collect data. The data comes from 5 companies in Chengdu, China. The questionnaire is distributed and collected with the cooperation of the human resources department.

\subsection{Measures}

This study adopted the Likert five-item scales to measure personal values, environmental self-accountability, green brand identity and self-monitoring. We mainly refer to authoritative scale. In order to measure consumers' selfimprovement values, we employed the 3 -item scale developed by Pepper [6]. The Cronbach's Alpha for this scale was 0.71 . In order to measure consumers' environmental self-accountability, we have borrowed from the 3-item scale developed by Rowe [7]. The Cronbach's Alpha coefficient of this scale is 0.890 . We refer to the 8-item scale to measure consumer acceptance of green brands developed by Cha [8]. The Cronbach's Alpha coefficient of this scale is 0.950 . In order to measure the self-monitoring characteristics of consumers, we used the 7-item scale developed by Alnakhli for reference [9]. The Cronbach's Alpha coefficient of this scale is 0.928 .

\section{Hypothesis Testing}

The first is the main effect test, which is the influence of self-improvement values on green brand identity. Taking green brand identity as the antecedent variable, Model 5 is a regression model for consumers' green brand identity after adding independent variables (self-improvement values). It can be seen from Table 1 that in Model 5, selfimprovement values have a significant positive impact on consumers' identification with green brands $(\beta=0.069$, $\mathrm{p}<0.01$ ), so Hypothesis 1 is supported by the data.

The second is the intermediary effect test, it can be seen from Table 1 that in Model 2, consumers' selfimprovement values have a significant positive impact on consumers' environmental self-accountability $(\beta=0.789$, $\mathrm{p}<0.01$ ), and hypothesis 3 is supported by data; In Model 6 , consumers' environmental self-accountability has a significant positive impact on their identification with green brands $(\beta=0.74, p<0.01)$, so Hypothesis 2 is supported by data; After adding the intermediary variable (environmental self-accountability), in Model 7, The influence of consumers' self-improvement values on green brand identity $(\beta=0.285, \quad p<0.01)$ continues to be 
significant. In addition, environmental self-accountability also has a significant positive impact on consumers' recognition of green brands $(\beta=0.74, p<0.01)$. Therefore, Hypothesis 4 is supported by the data.

Finally, there is a moderating effect test, it can be seen from Table 1 that in Model 3, after the adjustment variable (self-monitoring) is added, consumers' self-improvement values still have a significant positive impact on environmental self-accountability $(\beta=0.504, p<0.01)$. At the same time, after the interaction between consumers' self-improvement values and consumers' self-monitoring, the environmental self-accountability of consumers values and consumers' self-monitoring, the values and consumers' self-monitoring, the values and consumers' self-monitoring, the environmental self-accountability of consumers $(\beta=0.175, p<0.01)$ has a significant positive impact. Hypothesis 5 is supported by data.

At the same time, we found that the estimated mediation point with adjustment is 0.0631 , and the $95 \%$ confidence interval is $[0.01025,0.0316]$, excluding zero. That is, as the value of the self-monitoring trait changes from one standard deviation below the confidence interval is $[0.01025,0.0316]$, excluding zero. That is, as the value of the self-monitoring trait changes from one standard deviation below the average to a standard deviation above the average, the mediating role of environmental selfaccountability increases significantly. Hypothesis 6 is supported by data.

Table 1. Regression Test of Environmental Self-accountability and Green Brand Identity ( $n=297)$

\begin{tabular}{|c|c|c|c|c|c|c|c|}
\hline & \multicolumn{3}{|c|}{ Environmental Self-accountability } & \multicolumn{4}{|c|}{ Green Brand Identity } \\
\hline & Model 1 & Model 2 & Model 3 & Model 4 & Model 5 & Model 6 & Model 7 \\
\hline Sex & -0.055 & -0.065 & -0.061 & 0.050 & 0.041 & 0.091 & 0.075 \\
\hline Age & -0.089 & -0.032 & -0.02 & 0.015 & 0.065 & 0.081 & 0.081 \\
\hline Education & -0.088 & 0.034 & 0.023 & 0.042 & -0.005 & -0.023 & -0.022 \\
\hline SI & & $0.789^{* *}$ & $0.504^{* *}$ & & $0.69^{* *}$ & & $0.285^{* *}$ \\
\hline ES & & & & & & $0.74^{* *}$ & $0.512^{* *}$ \\
\hline SM & & & $-0.235^{* *}$ & & & & \\
\hline $\mathrm{SI} * \mathrm{SM}$ & & & $0.175^{* *}$ & & & & \\
\hline $\mathrm{R} 2$ & 0.023 & 0.637 & 0.684 & 0.004 & 0.473 & 0.538 & 0.568 \\
\hline $\begin{array}{l}\text { Adjusted } \\
\text { R2 }\end{array}$ & 0.013 & 0.632 & 0.677 & -0.006 & 0.466 & 0.532 & 0.561 \\
\hline $\mathrm{F}$ & 2.336 & $128.154^{* *}$ & $104.432^{* *}$ & 0.363 & $65.512^{* *}$ & 85.136 & $76.603^{* *}$ \\
\hline
\end{tabular}

Notes: "SI" indicates Self-improvement values, "ES" indicates Environmental Self-accountability, "SM" indicates Self-monitoring; **: p<0.01

\section{Conclusion}

This article explores the influence of self-improvement values on green brand identity, and the conclusions are as follows: First, consumers' self-improvement values positively affect consumers' recognition of green brands; Second, the environmental self-accountability positively affects consumers' recognition of green brands; Third, the environmental self-accountability plays a significant role as an intermediary mechanism in the "consumer valuesgreen brand identity" relationship chain; Fourth, the selfmonitoring characteristics of consumers positively regulate the relationship between "consumer valuesenvironmental self-accountability" and strengthen the mediating role of environmental self-accountability.

\section{Acknowledgement}

This work is supported by the Blockchain-Based Liquor Anti-Counterfiting Information Platform R\&D Fund [2018CDLZ-31].

\section{References}

1. Coelho, P., Rita, P., \& Santos, Z. On the relationship between consumer-brand identification, brand community, and brand loyalty. Journal of Retailing and Consumer Services, 43, 101-110. (2018)

2. Tuškej, U., Golob, U., \& Podnar, K. The role of consumer-brand identification in building brand relationships. Journal of Business Research, 66(1), 53-59. (2013)

3. Annika, N., \& Garvill, J. Value Structures Behind 
Proenvironmental Behavior. Environment and Behavior - ENVIRON BEHAV, 34(6), 740-756. (2002)

4. Peloza, J., White, K., \& Shang, J. Good and GuiltFree: The Role of Self-Accountability in Influencing Preferences for Products with Ethical Attributes. Journal of Marketing, 77(1), 104-119. (2013)

5. Dhiman, A., Sen, A., \& Bhardwaj, P. Effect of SelfAccountability on Self-Regulatory Behaviour: A Quasi-Experiment. Journal of Business Ethics, 148.

6. Pepper, M., Jackson, T., \& Uzzell, D. An examination of the values that motivate socially conscious and frugal consumer behaviors. International Journal of Consumer Studies, 33(2), 126-136. (2009)

7. Rowe, Z., Wilson, H., Dimitriu, R., Breiter, K., \&
Charnley, F. The Best I Can Be: How SelfAccountability Impacts Product Choice in Technology-Mediated Environments. Psychology and Marketing, 34(5). (2017)

8. Cha, M.-K., Yi, Y., \& Bagozzi, R. Effects of Customer Participation in Corporate Social Responsibility (CSR) Programs on the CSR-Brand Fit and Brand Loyalty. Cornell Hospitality Quarterly, 57(3). (2015)

9. Alnakhli, H., Singh, R., Agnihotri, R., \& Itani, O. From cognition to action: the effect of thought selfleadership strategies and self-monitoring on adaptive selling behavior. Journal of Business \& Industrial Marketing, ahead-of-print(ahead-of-print). (2020) 